\title{
Bilaminar Embryonic Disc
}

National Cancer Institute

\section{Source}

National Cancer Institute. Bilaminar Embryonic Disc. NCI Thesaurus. Code C34112.

An embryonic structure that appears as a disc composed of epiblast and hypoblast sac. 